\title{
Mutated Barley: A Climate Change Adaptation Strategy for Food Security and Biodiversity Management
}

\author{
Habibah S. Al-Menaie*, Ouhoud Al-Ragam \\ Kuwait Institute for Scientific Research, Safat, Kuwait \\ Email: ${ }^{*}$ hmanaie@kisr.edu.kw
}

Received 7 May 2015; accepted 22 August 2015; published 25 August 2015

\begin{abstract}
Increased agricultural production under the harsh environmental conditions with limited water resources and scarce natural resources is a major challenge in arid regions like Kuwait. The implementation of sustainable agricultural practices holds paramount importance in delivering better agricultural environment for increased production. Barley (Hordeum vulgare) is one among the most dependable cereal crops under saline and drought conditions. Mutant barley genotypes that have evolved under stress conditions using the improved genetic resources have the desired morphological, physiological and agronomic traits. As Kuwait lack local barley genotypes, it is important to find suitable barley genotypes adaptable to drought and salinity, with high crop water productivity. In this study, several mutant barley varieties were screened for better performance under drought and salinity, with high feed quality. The growth performance and the nutritive value of twelve different barley cultivars were evaluated under both fresh and brackish water irrigation in Kuwait. The seeds of the superior lines were multiplied for fodder production trials and their nutritive value was evaluated in animal production systems. It was found that two parental lines Gustoe and California Marriot and two mutant barley genotypes ari-e.228 and Golden Promise produced high grain yield of 3 - 4 ton/ha. The mutant genotype Golden Promise was the most tolerant, while ari-e.156 was the most susceptible genotype to saline stress. Both proximate analysis and animal feeding trial showed that the dry matter content of the air dry straws varied from $91.26 \%$ to $93.35 \%$. The crude fat contents were within the acceptable range $(1.13 \%$ to $1.93 \%$ ), and high concentrations of ash and crude protein were found in straw in all genotypes. Thus, the evolution of farming systems that are economically viable, competitive, sustainable and environmental friendly improves the production efficiency, productivity and product quality of various crops.
\end{abstract}

\section{Keywords}

Mutant Barley, Fresh Water Irrigation, Brackish Water Irrigation

\footnotetext{
*Corresponding author.
} 


\section{Introduction}

The agricultural sector of Kuwait is facing several challenges, such as drought, heat stress, and soil salinities which lead to decreased crop production to a great extent. Insufficient freshwater resources for irrigation and lack of efficient soil and water management practices have affected the growth of agricultural production. Kuwait does not possess permanent surface water and underground freshwater resources. Additionally, the quantity and quality of groundwater had been deteriorating. Excessive water use and poorly designed drainage systems are causing water logging and salinity in surface irrigation. At present, over $95 \%$ of its total feed requirement is of imported origin. Therefore, a sustainable and economically viable crop production system is essential to increase the local food and feed production.

The cultivation of multipurpose crops, which are adaptable to the harsh environmental conditions, is vital to support the efficient production of food and feed. Kuwait's Agricultural Master Plan projected that demands and prices for livestock concentrate would increase by three to six fold during the next 15 yr. Barley (Hordeum vulgare), a major crop cultivated worldwide, is primarily used as a food, feed and in malting industries (Druka et al., 2011) [1]. It is the most drought- and salt-tolerant of the small grain cereals, and is highly preferred by the farmers worldwide (Jana and Wilen, 2005) [2]. Globally, it ranks fourth in cereal production after maize, wheat, and rice (FAO, 2013) and is included in the list of the priority crops in the Agriculture Master Plan of the State of Kuwait (KISR, 1996) [3]. Production of new varieties with desirable characteristics such as increased yield and nutrition, tolerance to biotic and abiotic stresses, opens great scope towards crop improvement in Kuwait. Mutant crop varieties with increased yield improved nutrient content, and resource use efficiency have been developed by using induced mutagenesis (Parry et al., 2009) [4].

In this study, a comparative evaluation of the growth response of twelve different barley varieties under two different types of irrigation water resources (fresh and brackish water irrigation) was performed. Since barley is a useful food and feed crop in the dry condition of Kuwait, this study may help establish the baseline for agronomic practice that would maximize the yield and nutritional value of cereals as dual-purpose food and feed crops, using a range of mutant barley varieties.

\section{Materials and Method}

The field experiment was carried out in the Agricultural Research Station at Kabd, Kuwait. Sprinkler irrigation system was established for supplying brackish water to the experimental site. Before the commencement of the experiment, water samples were taken to determine the total dissolved solids (TDS) and electrical conductivity (EC). A trial series design was used to study the effect of irrigation water (fresh and brackish) on twelve cultivars; two mutant cultivars Golden Promise (ari-e.GP) and ari-e.156; the parental lines Maythorpe, Bonus, California Marriot, and Gustoe; and six local promising cultivars namely, Kuwait 1, 2, 3, 4, 5, and 6. The cultivars were sown in parallel rows with one replicate per cultivar, occupying $2.5 \mathrm{~m} /$ row, each replicate consisting of five seeds, spaced at $50-\mathrm{cm}$ intervals, and each treatment plot, being replicated five times. A similar plot was sown as a control with freshwater irrigation. Nitrogen fertilizer was added in the form of ammonium nitrate (32.5\%) with a rate of $100 \mathrm{~kg} \mathrm{~N} / \mathrm{ha}$ in ten equal doses with seven-day interval. Potassium was added in the form of potassium nitrate (47\%) in two equal doses at tillering and heading stages. All other recommended cultural practices were applied to the experiment during the growing season. Data on heading stage, maturity stage, 1000 kernel weight, and biological yield were recorded and analyzed using SPSS.

For chemical analysis of barley straw and grain, the barley grains and straws of different cultivars were harvested after the grains were matured and leftover plants were almost dried in the field. The straws were oven dried at $70^{\circ} \mathrm{C}$ for $72 \mathrm{~h}$ and analyzed according to Association of Official Analytical Chemists (2002) methods [5].

\section{Results and Discussion}

\subsection{Heading Stage}

The effect of irrigation on the days to heading stage was studied in twelve different cultivars, and it was found that the type of irrigation water significantly affected the days to heading in the barley cultivars under study. The TDS and EC of the water sample were $934 \mathrm{mg} / \mathrm{l}$ and $1.877 \mathrm{~ms} / \mathrm{cm}$ respectively, which are in the acceptable range. Under freshwater irrigation, Kuwait 4 exhibited least days to heading with no significant difference over Kuwait 3, Bonus and ari-e.GP, whereas under brackish water irrigation, Kuwait 5 exhibited the least value with 
no significant difference from Kuwait 4 and Kuwait 6 (Table 1). The interaction study between irrigation and cultivars also revealed the least days to heading in Kuwait 5 with no significant difference over Kuwait 4 and Kuwait 6 under brackish water irrigation (Table 1).

In an arid country like Kuwait, cultivars with reduced vegetative state and increased grain yield is preferred owing to unfavorable drought and heat stress.

\subsection{Maturity Stage}

The study on the effect of irrigation on maturity dates showed that the brackish water irrigation decreased the maturity date significantly by $21 \mathrm{~d}$. Brackish irrigation caused a decrease in the maturity dates for all cultivars. The decrease ranged from $12 \%$ in Gustoe and Bonus to $22 \%$ in Kuwait 5 . The earliest maturity was obtained by Kuwait 3, Kuwait 4, and Golden promise (119 d) under brackish water irrigation (Table 2). The analysis of interaction between irrigation and cultivars showed that the cultivars Kuwait 1 and Kuwait 2 hold the earliest maturity date without significantly varying from Kuwait 3, Kuwait 5, Kuwait 6 and California cultivars under brackish water irrigation.

\subsection{One Thousand Kernel Weight}

The analysis of effect of type of irrigation water on number of 1000 kernel weight showed that the brackish water significantly decreased kernel weight by $29 \%$ (Table 3 ). The interaction study between irrigation and cultivars recorded the heaviest grain in Gustoe under freshwater irrigation (5.99 g).

\subsection{Biological Yield}

The brackish water irrigation significantly decreased biological yield by $55 \%$. The interaction between irrigation and cultivars showed that brackish water decreased biological yield for all cultivars, but this decrease was not significant for Kuwait 2, Kuwait 5, Golden promise, ari-e.156, Maythorpe, and Bonus (Table 4). In addition, Kuwait 2 had the highest biological yield under brackish irrigation.

Table 1. Effect of irrigation on heading stage.

\begin{tabular}{|c|c|c|c|}
\hline Cultivar & Fresh Irrigation & Brackish Irrigation & Mean \\
\hline Kuwait 1 & 106.25 & 90 & 98.13 \\
\hline Kuwait 2 & 111.35 & 89.4 & 100.48 \\
\hline Kuwait 3 & 103.18 & 89.2 & 96.19 \\
\hline Kuwait 4 & 102 & 80.5 & 91.25 \\
\hline Kuwait 5 & 115 & 79.8 & 97.4 \\
\hline Kuwait 6 & 105.4 & 80.4 & 92.9 \\
\hline ari-e.GP & 102.42 & 88.6 & 95.51 \\
\hline ari-e.156 & 107 & 88.2 & 97.6 \\
\hline Maythorpe & 109.12 & 92.4 & 100.76 \\
\hline Bonus & 103.32 & 89.6 & 96.46 \\
\hline California Marriot & 104.8 & 84.8 & 94.8 \\
\hline Gustoe & 106.54 & 90 & 98.27 \\
\hline Mean & 106.37 & 86.9 & 96.6 \\
\hline \multicolumn{2}{|c|}{ LSD 0.05 for Irrigation } & \multicolumn{2}{|c|}{0.93} \\
\hline \multicolumn{2}{|c|}{ Cultivars } & \multicolumn{2}{|c|}{2.18} \\
\hline \multicolumn{2}{|c|}{ Irri. * Cultivars } & \multicolumn{2}{|c|}{2.73} \\
\hline
\end{tabular}

LSD: Least significant difference. 
Kuwait 1, Maythorpe, and Bonus were the most sensitive cultivars to saline stress.

\subsection{Chemical Analysis of Barley Forage and Grain}

Proximate analysis of barley straws and grains which included estimation of dry matter (DM), ash, crude protein (CP) and fat content was conducted to determine the composition and grains of different barley cultivars under study.

The DM content of the air dry straws varied from $91.26 \%$ to $93.35 \%$ with no significant differences. The crude fat content was within the acceptable range (1.13\% to $1.93 \%)$. Exceptionally, very high concentrations of ash and crude protein were found in all varieties of straw. Ash content ranged from $16.12 \% \pm 0.06 \%$ to $24.79 \% \pm$ $0.29 \%$ (Table 6). It was expected that the desert sand and silica accumulated in the barley plants during the growing periods resulted in high inorganic components in the straws. The variations due to barley cultivars could also be attributed to the amount of sands and silica deposition in the straws. The most important observations were the unexpected high concentrations of crude protein in straws ranging from $10.08 \% \pm 0.43 \%$ in cv. Foma to $13.48 \% \pm 0.06 \%$ in cultivar Gustoe. Normal barley straws were found to contain an average of $4.3 \%$ CP on DM basis (NRC, 1984). The straws (barley) commercially sold in Kuwait contained CP ranging from $2 \%$ to $4 \%$ in DM (NRC, 1984).

Out of the 15 cultivars, 12 barley grain samples were analyzed (Table 7) for two parameters (CP and ash). Ash content ranged from $2.44 \% \pm 0.35 \%$ to $4.29 \% \pm 0.05 \%$ with no appreciable variations between the cultivars of barley grains. Exceptionally high concentrations of CP were found in all cultivars of barley grains ranging from $15.3 \% \pm 0.08 \%$ to $24.32 \% \pm 0.14 \%$ on DM basis. These results were corresponded on DM basis with high concentrations of CP in straws (Table 7). Barley grains usually contain $10.8 \%$ to $13.5 \% \mathrm{CP}$, depending on the sources or place of origin (NRC, 1984).

In Table 6 and Table 7, the CP concentrations of barley straws and grains were two to three times higher than those reported in the feed composition tables of NRC (1984) [6]. It was observed by Hollena et al. (2006) [7] that the cereal cultivars were significantly influenced by the nitrogen fertilization during their growing period.

Table 6. Proximate composition of barley straws.

\begin{tabular}{|c|c|c|c|c|}
\hline \multicolumn{5}{|c|}{ Analytical Variables (\%) } \\
\hline Barley Straws & \multirow{2}{*}{$\mathrm{DM} \pm \mathrm{S} . \mathrm{D}$} & \multicolumn{3}{|c|}{ On DM Basis } \\
\hline Cultivars $^{\#}$ & & Ash \pm S.D & $\mathrm{CP} \pm \mathrm{S} . \mathrm{D}$ & Fat \pm S.D \\
\hline Kuwait 1 & $91.26 \pm 0.18$ & $18.50 \pm 0.24$ & $11.56 \pm 0.30$ & $1.64 \pm 0.24$ \\
\hline Kuwait 2 & $92.37 \pm 0.22$ & $17.32 \pm 0.18$ & $10.49 \pm 0.17$ & $1.68 \pm 0.21$ \\
\hline Kuwait 3 & $92.03 \pm 0.042$ & $16.12 \pm 0.06$ & $11.43 \pm 0.13$ & $1.24 \pm 0.63$ \\
\hline Kuwait 4 & $91.53 \pm 0.53$ & $20.20 \pm 0.45$ & $10.66 \pm 0.13$ & $1.73 \pm 0.39$ \\
\hline Kuwait 5 & $93.35 \pm 0.10$ & $21.28 \pm 0.22$ & $10.16 \pm 0.54$ & $1.93 \pm 0.23$ \\
\hline Kuwait 6 & $91.26 \pm 0.44$ & $19.48 \pm 0.52$ & $11.26 \pm 0.14$ & $1.74 \pm 0.30$ \\
\hline ari-GP & $92.92 \pm 0.07$ & $22.83 \pm 0.47$ & $11.51 \pm 0.26$ & $1.51 \pm 0.11$ \\
\hline ari-e.1 & $92.31 \pm 0.34$ & $22.58 \pm 0.59$ & $12.04 \pm 0.10$ & $1.49 \pm 0.04$ \\
\hline ari-e.156 & $92.23 \pm 0.27$ & $24.79 \pm 0.68$ & $12.21 \pm 0.40$ & $1.57 \pm 0.16$ \\
\hline ari-e.228 & $91.85 \pm 0.10$ & $18.31 \pm 0.36$ & $11.23 \pm 0.23$ & $1.74 \pm 0.10$ \\
\hline Maythorpe & $91.93 \pm 0.31$ & $24.29 \pm 0.43$ & $10.10 \pm 0.17$ & $1.41 \pm 0.04$ \\
\hline Bonus & $91.56 \pm 0.42$ & $22.99 \pm 0.48$ & $12.08 \pm 0.43$ & $1.51 \pm 0.06$ \\
\hline Foma & $93.04 \pm 0.19$ & $20.46 \pm 0.04$ & $10.08 \pm 0.43$ & $1.70 \pm 0.07$ \\
\hline California Marriot & $92.21 \pm 0.07$ & $19.23 \pm 0.24$ & $10.3 \pm 0.29$ & $1.13 \pm 0.05$ \\
\hline Gustoe & $92.11 \pm 0.23$ & $17.71 \pm 0.45$ & $13.48 \pm 0.24$ & $1.43 \pm 0.23$ \\
\hline
\end{tabular}

DM: Dry matter, S.D: Standard deviation, CP: Crude protein, EE: Ether extract. 
Table 7. Proximate composition of barley grains.

\begin{tabular}{ccc}
\hline Cultivars & Ash (\%) & CP (\%) \\
\hline Kuwait 1 & $3.65 \pm 0.09$ & $18.73 \pm 0.19$ \\
Kuwait 2 & $3.15 \pm 0.40$ & $15.30 \pm 0.08$ \\
Kuwait 3 & $2.97 \pm 0.01$ & $16.82 \pm 0.23$ \\
Kuwait 4 & $3.24 \pm 0.03$ & $20.69 \pm 0.06$ \\
Kuwait 5 & $2.44 \pm 0.38$ & $19.62 \pm 0.65$ \\
Kuwait 6 & $3.64 \pm 0.13$ & 19.810 .05 \\
ari-e.GP & $3.13 \pm 0.06$ & $23.58 \pm 0.03$ \\
ari-e.1 & -- & -- \\
ari-e.156 & -- & -- \\
ari-e.228 & $4.29 \pm 0.05$ & $17.72 \pm 0.02$ \\
Maythorpe & -- & - \\
Bonus & $3.53 \pm 0.04$ & 22.210 .11 \\
Foma & $3.92 \pm 0.06$ & $24.32 \pm 0.14$ \\
California Marriot & $4.05 \pm 0.07$ & $21.91 \pm 0.31$ \\
Gustoe & $3.42 \pm 0.05$ & $23.34 \pm 0.04$ \\
\hline
\end{tabular}

CP: Crude protein.

The rice straws grown under the additional nitrogen fertilization had almost double the concentration of CP compared to fertilization without or low N (Hollena et al., 2006). The results obtained in this study are consistent with those findings in which CP of grains could be increased by nitrogen fertilization.

\subsection{Palatability of Straws}

Palatability or acceptability of any feed or combination of several feeds refers to the combination of factors that result in a feed or combination of feeds being well-liked and eaten by the animals with relish (Ensminger et al., 1990) [8]. The main purpose of the present study was to examine the acceptability or palatability of barley straws produced in Kuwait. The consumption rates of straws of varieties Kuwait 1, Kuwait 2, Kuwait 3, Kuwait 4, Golden promise, ari-e.1, ari-e.156, ari-e.228, Maythrope, Bonus, Foma, California Marriot, and Gustoe by lambs were $100 \%$ and $95 \%$ in Kuwait 5, and Kuwait 6. The differences were not significant based on the preliminary palatability of sheep. Further studies are in progress to investigate the digestibility of cultivated barley straws on livestock.

\section{Conclusion}

Unchecked population growth, rapid industrialization, and ecological overshoot could result in unpredictable climatic changes, marked with abiotic stress factors such as aridity and soil salinity, posing major threats to biodiversity, world stability, and food security. A comparative evaluation of the growth response of local and mutant barley cultivars was carried out under fresh and brackish water irrigation in Kuwait's environmental conditions. The local promising cultivars exhibited high adaptability to local environmental conditions and had good performance under freshwater irrigation. In addition, two parental lines and two mutant barley varieties, Gustoe, California Marriot, ari-e.228, and Golden Promise produced high-grain yield with no significant differences from the local materials. Brackish water irrigation decreased the time period taken to attain the heading and maturity stages in the life cycle of barley. Besides, biological yield and grain yield were reduced under brackish water irrigation. Stress susceptibility index showed that the cultivars Gustoe, Golden Promise, Kuwait 5, Kuwait 2, and California Marriot were the most tolerant cultivars to saline stress; while Kuwait 4, Kuwait 6, ari-e.156, Kuwait 3, Kuwait 1, Maythorpe, and Bonus were the most sensitive cultivars to saline stress. Further studies are required to investigate the stability of promising lines and mutant barley cultivars under Kuwait's conditions, as 
plant drought and salinity tolerance are highly complex traits that involve multiple genetic, physiological, and biochemical mechanisms and physiology.

\section{References}

[1] Druka, A., Sato, K. and Muehlbauer, G.J. (2011) Genome Analysis: The State of Knowledge of Barley Genes. In: Ullrich, S.E., Ed., Barley: Production, Improvement, and Uses, Blackwell Publishing Ltd., United Kingdom. http://dx.doi.org/10.1002/9780470958636.ch4

[2] Jana, S. and Wilen, R.W. (2005) Breeding for Abiotic Stress Tolerance in Barley. In: Ashraf, M. and Harris, P.J.C., Eds., Abiotic Stresses: Plant Resistance through Breeding and Molecular Approaches, Food Product Press, New York.

[3] KISR (1996) Agricultural Master Plan of the State of Kuwait (1995-2015): Plan Overview. Kuwait Institute for Scientific Research, Kuwait.

[4] Parry, M.A., Pippa, J.J., Bayon, M.C., Katie, T., Hernandez-Lopez, A., Marcela, B., Mariann, R., Walid, H., Al-Yassin, A., Ouabbou, H., Labhilili, M. and Phillips, A.L. (2009) Mutation Discovery for Crop Improvement. Journal of Experimental Botany, 60, 2817-2825. http://dx.doi.org/10.1093/jxb/erp189

[5] AOAC (2002) Official Methods of Analysis of AOAC International. 16th Edition, AOAC, Arlington.

[6] NRC (1984) Nutrient Requirements of Beef Cattle. 6th Edition, National Research Council, National Academy Press, Washington DC.

[7] Hollena, N., Halim, A. and Ramlan, M.A. (2006) The Effect of Nitrogen Fertilization Levels on the Straw Nutritive Quality of Malaysian Rice Varieties. Journal of Agronomy, 5, 482-491. http://dx.doi.org/10.3923/ja.2006.482.491

[8] Ensminger, M.E., Oldfield, J.E. and Heinemann, W.W. (1990) Feeds and Nutrition. The Ensminger Publishing Company, Clovis. 